\title{
A rheological characterisation of mashed potatoes enriched with soy protein isolate
}

\author{
María Dolores Alvarez , Cristina Fernández, María Dolores Olivares, Wenceslao Canet
}

\begin{abstract}
A B S T R A C T
The effect of the addition of soy protein isolate (SPI) $\left(0,15,30,45\right.$ and $\left.60 \mathrm{~g} \mathrm{~kg}{ }^{1}\right)$ on viscoelastic properties, large deformation measurements and microstructure of fresh (FM) and frozen/thawed (F/TM) mashed potatoes was investigated. Rheological data showed weak gel behaviour for both FM and F/TM potatoes without and with added SPI together with a significant decrease of system viscoelasticity ( $G^{\prime}$ and $G^{\prime \prime}$ ) with increasing SPI volume fraction, primarily attributed to the no interaction between the amylose/amylopectine matrix and the dispersed SPI particles or aggregates as revealed by scanning electron microscopy (SEM). Micrographs also showed that SPI formed white coarse aggregates. A freeze/thaw cycle produced a more significant decrease in viscoelastic functions, due to superior aggregation of denatured SPI and reduced water activity. In F/TM samples, high correlations between small and large deformation measurements were found. Results may be useful for technological applications in SPI-enriched mashed potatoes.
\end{abstract}

\section{Introduction}

In recent years, considerable interest has been given to the study of protein-polysaccharide mixtures in both the industrial and academic sectors (Zhu et al., 2008). Protein and starch are present in many foods and they contribute to their structural and textural characteristics through their aggregation and gelation behaviour. The overall texture and stability of food products depend not only on the properties of proteins and polysaccharides, but also on the nature and strength of protein/polysaccharide interaction (Hemar, Hall, Munro, \& Singh, 2002). Therefore, a knowledge of the mechanisms of interactions occurring in protein-polysaccharide systems is important in developing desirable properties in food products. In addition, great potential remains in mixing polysaccharides with globular proteins, soy protein isolate.

Potato starches are attractive food ingredients because they are both natural and safe, whereas soy proteins are typical vegetable proteins with health-enhancing activities. Soy-based food consumption has been on the rise since the US Food and Drug Administration (FDA) decided to accept soy protein health claims linking the intake of products high in soy protein with several potential health benefits. Functional properties of soybean protein isolates (SPI) reflect the composition, structure, denaturation, and degree of aggregation of their major components: 7S ( $\beta$-conglycinin) and 11S (glycinin) globulins (Puppo, Sorgentini, \& Añón, 2000).
An important functional property in SPI is gelation during thermal treatment with desirable water holding capacity. Heat treatment induces dissociation, denaturation and aggregation of soy protein (Sorgentini, Wagner, \& Añón, 1995). Freezing also brought about some changes in the processing characteristics of soybeans. When the soy protein solution was frozen, the proteins became partially insoluble due to the polymerisation of protein molecules through the formation of intermolecular disulphide bonds (Hashizume, Kakiuchi, Koyama, \& Watanabe, 1971). However, only a few studies have been carried out to characterise the freezing effect on soy protein properties (Li et al., 2007).

There is a possibility of using SPIs in combination with potato products, not only to provide a useful alternative to other highly nutritious and healthy food products, but also to improve the physicochemical, functional and sensory characteristics of potato products in general. Research on the influence of food ingredients and food processing conditions on SPI performance in specific foods is scarce. Mashed potatoes (MP) are a promising nutritious vehicle for incorporating soy into the diet. Nevertheless, FM potatoes themselves make up a combined system of native potato starch, denatured milk protein, water and salt plus added cryoprotectants [xanthan gum (XG) and kappa-carrageenan $(\kappa-C)$ ] as the product is intended to be frozen. During the MP preparation procedure (heating), starch, XG, $\kappa-\mathrm{C}$ and protein undergo physicochemical changes, such as starch gelatinization and solubiliasation, protein denaturation and hydrogen bond rupture. After heating, when MP samples are cooled to $55^{\circ} \mathrm{C}$, changes in starch, XG and $\kappa-\mathrm{C}$ polymers occur and continuous and dispersed phase properties are influenced. Consequently, as complex interactions can 
influence the properties of these mixtures, structural changes produced in MPs as a result of SPI addition, heating and freeze/thaw cycle need to be monitored directly in the MP matrix.

Many food products are macromolecular gels containing dispersed particles (fillers) (van Vliet, 1988). The influence of these particles on the rheological properties of a gel can be drastic, depending on their concentration and rheological properties and on the extent of filler-gel matrix interaction. In MPs with added SPI, the rheological properties will depend on whether the SPI gel was formed or not, and on gel type, both factors being dependent on the degree of denaturation and the extent of protein aggregation reached (Sorgentini et al., 1995).

Small amplitude oscillatory shear (SAOS) measurements afford the measurement of dynamic rheological functions, without altering the internal network structure of materials tested (Alvarez, Fernández, Solas, \& Canet, 2011; Campo-Deaño, Tovar, \& Borderías, 2010). The gelation behaviour and characteristics of SPI-enriched MPs during heating and freeze/thaw process could be well represented by SAOS measurements where the strain is restricted to less than $5 \%$. However, since foodstuffs are subjected to large deformations, priority should be given to analysing both linear and nonlinear viscoelastic ranges to determine product performance under actual processing conditions and consumption (Navarro, Martino, \& Zaritzky, 1997).

Given the demand for new functional ingredients in the food industry, characterisation of MPs with added SPIs is worthwhile, as it will aid in extending its possible uses and added value to this protein. The objective of the present work was to evaluate the effect of the SPI concentration on viscoelastic properties, large deformation measurements and microstructure of FM and F/TM potatoes and accordingly to highlight the extent upon which SPI can be employed without negative changes in mashed potatoes texture characteristics.

\section{Materials and methods}

\subsection{Materials}

The potatoes used were tubers (Solanum tuberosum, L., cv Kennebec) from Aguilar de Campoo (Burgos, Spain). Readily dispersible SPI with the trade name PRO-FAM ${ }^{\circledR} 646$ (ADM, Netherlands) was used in this study without more purification. The proximate composition $(\mathrm{g} / 100 \mathrm{~g})$, as specified by the producer, was as follows: protein $(N \times 6.25)>90$, moisture $<6.0$, fat $<5$, and ash $<5$. XG (Keltrol F [E]) and $\kappa-C$ (GENULACTA carrageenan type LP-60) were donated by Premium Ingredients, S.L. (Girona, Spain). The FDA has determined that diets containing $25 \mathrm{~g}$ of soy protein (four daily servings of $6.25 \mathrm{~g}$ soy protein) can reduce levels of low-density lipoproteins (bad cholesterol) by as much as $10 \%$ (Federal Register, 1998). Range-finding experiments were carried out by adding four different concentrations of SPI $\left(15,30,45\right.$ and $\left.60 \mathrm{~g} \mathrm{~kg}^{-1}\right)$ to the MPs, and MPs without added SPI were also prepared $\left(0 \mathrm{~g} \mathrm{~kg}^{-1}\right)$ for use as controls. Therefore, an MP serving of $200 \mathrm{~g}$ with added SPI concentrations of $15-60 \mathrm{~g} \mathrm{~kg}^{-1}$ would provide from $3-12 \mathrm{~g}$ of soy protein respectively. Though the quantity of $25 \mathrm{~g}$ soy protein seems high, soy protein is actually easy to consume, and there are many examples of different foods with high soy protein content (http://www.soya.be/soy-protein-health-claim.php). In Table 1 each of the FM and F/TM tested samples can be easily identified by the notations used.

\subsection{Preparation of MP samples}

Tubers were manually washed, peeled and diced. MPs were prepared in $\sim 1350-\mathrm{g}$ batches from $607.7 \mathrm{~g} \mathrm{~kg}^{-1}$ of potatoes,
$230.8 \mathrm{~g} \mathrm{~kg}^{-1}$ of semi-skimmed in-bottle sterilized milk $153.8 \mathrm{~g} \mathrm{~kg}^{-1}$ of water, $7.7 \mathrm{~g} \mathrm{~kg}^{-1}$ of salt $(\mathrm{NaCl})$ and $1.5 \mathrm{~g} \mathrm{~kg}^{-1}$ of either $\kappa$-C or XG (Alvarez, Fernández, \& Canet, 2009), using a TM 31 food processor (Vorwerk España, M.S.L., S.C., Madrid, Spain). The ingredients were first heated to $90^{\circ} \mathrm{C}\left(17^{\circ} \mathrm{C} \mathrm{min}-1\right)$ and kept at $90^{\circ} \mathrm{C}$ for $30 \mathrm{~min}$ (blade speed: $0.10 \mathrm{~g}$ ). Shearing was performed with a propeller. The amount of evaporated liquid was determined by weighing the ingredients before and after the first cooking and then replaced by adding milk. In terms of processibility, there were serious difficulties in cooking SPI together with the rest of the ingredients, especially when SPI levels were over $45 \mathrm{~g} \mathrm{~kg}^{-1}$. The SPI concentration of $15-60 \mathrm{~g} \mathrm{~kg}^{-1}$ which had previously been hydrated at a ratio of SPI to water of 1:5 was then added at this point. Water used to hydrate SPI was removed from initial water content $\left(153.8 \mathrm{~g} \mathrm{Kg}^{-1}\right)$. Next, all the ingredients were cooked for an additional $5 \mathrm{~min}$ at $90^{\circ} \mathrm{C}$. The mash was ground for $40 \mathrm{~s}$ (blade speed: $80 \mathrm{~g}$ ) and $20 \mathrm{~s}$ (blade speed: $450 \mathrm{~g}$ ), and then homogenised immediately through a stainless steel sieve (diameter $1.5 \mathrm{~mm}$ ). The average final $\mathrm{pH}$ of MPs without and with added SPI ranged between 5.9 and 6.0, and remained unmodified by a freeze/thaw cycle. Two batches were continuously being prepared and blended and half of each fresh blend (FM potatoes) was analysed immediately whilst the other half was frozen and thawed (F/TM potatoes). Each MP composition was prepared twice but in different weeks to assure the appropriate experiment randomization.

\subsection{Freezing, thawing and heating procedures}

Following their preparation, MP samples were placed on flat freezing and microwave thawing trays and then frozen by forced convection with liquid nitrogen vapour in an Instron programmable chamber (model $3119-05,-70 / 250^{\circ} \mathrm{C}$ ) at $-60^{\circ} \mathrm{C}$ until their thermal centres reached $-24^{\circ} \mathrm{C}$. After freezing, the samples were packed in polyethylene plastic bags, sealed under light vacuum $(-0.05 \mathrm{MPa})$ on a Multivac packing machine (Sepp Haggenmüller KG, Wolfertschwenden, Germany), and placed in a domestic freezer for storage at $-24^{\circ} \mathrm{C}$. Packed frozen samples were then thawed in a Samsung M1712N microwave oven (Samsung Electronics S.A., Madrid, Spain) by heating for $20 \mathrm{~min}$ at an output power rating of $600 \mathrm{~W}$. After thawing, the temperature reached at the product thermal centre was measured in all cases $\left(+85 \pm 3^{\circ} \mathrm{C}\right)$. Samples were brought to $55^{\circ} \mathrm{C}$ by placing them in a Hetofrig CB60VS water-bath (Heto Lab Equipment A/S, Birkerød, Denmark). The sample testing temperature was maintained at $55^{\circ} \mathrm{C}$ as this is the preferred temperature for consumption of MPs (Alvarez et al., 2011).

\subsection{Rheological characterisation. Oscillatory shear measurements}

A Bohlin CVR 50 controlled stress rheometer (Bohlin Instruments Ltd., Cirencester, UK) was used to conduct SAOS experiments using a plate-plate sensor system with a $2 \mathrm{~mm}$ gap (PP40, $40 \mathrm{~mm}$ ) and a solvent trap to minimise moisture loss during tests. After loading the sample, there was a 5 -min waiting period to allow the sample to recover and reach $55{ }^{\circ} \mathrm{C}$. Temperature control at $55^{\circ} \mathrm{C}$ was achieved with a Peltier Plate system ( -40 to $+180^{\circ} \mathrm{C}$; Bohlin Instruments). In order to determine the linear viscoelastic (LVE) region, the first stress sweeps were run at a constant frequency $(\omega)$ of $1 \mathrm{rad} \mathrm{s}^{-1}$ over a shear stress range of 3$300 \mathrm{~Pa}$. The LVE range was limited to that amplitude range for which the complex modulus $\left(G^{*}\right)$ was constant (Navarro et al., 1997). Phase angle $\left(\delta,^{\circ}\right)$, storage modulus $\left(G^{\prime}, \mathrm{Pa}\right)$ and loss modulus $\left(G^{\prime \prime}, \mathrm{Pa}\right)$ values were also registered within the LVE region. The $G^{\prime}$ represents the non-dissipative component of mechanical properties and is characteristic of elasticity, while $G^{\prime \prime}$ represents the dissipative component of the mechanical properties and is 
Table 1

Dynamic measurements for linear and nonlinear viscoelastic ranges of fresh (FM) and frozen/thawed (F/TM) mashed potatoes with added SPI at different concentrations.

\begin{tabular}{|c|c|c|c|c|c|}
\hline System notation & $G_{\max }^{*}(\mathrm{~Pa})$ & $G_{\max }^{\prime}(\mathrm{Pa})$ & $\gamma_{\max }(-)$ & $G^{\prime} / G^{\prime a}$ & $\alpha$ \\
\hline FM-SPIO & $5273 \pm 56 a$ & $5019 \pm 45 a$ & $1.9410^{-3} \pm 9.0110-5 d$ & $1.04 \pm 0.005 \mathrm{a}$ & $0.194 \pm 0.003 b, c$ \\
\hline F/TM-SPIO & $5278 \pm 82 a$ & $5063 \pm 47 a$ & $1.2510^{-3} \pm 7.1110-5 \mathrm{~g}$ & $1.04 \pm 0.002 \mathrm{a}$ & $0.189 \pm 0.001 \mathrm{c}, \mathrm{d}$ \\
\hline FM-SPI15 & $4211 \pm 105 b$ & $3980 \pm 70 \mathrm{~b}$ & $0.9610^{-3} \pm 9.8710-5$ & $1.05 \pm 0.003 \mathrm{~b}$ & $0.190 \pm 0.002 c, d$ \\
\hline F/TM-SPI15 & $4309 \pm 95 b$ & $4110 \pm 97 b$ & $0.9410^{-3} \pm 1.2210-5 b$ & $1.04 \pm 0.002 \mathrm{a}$ & $0.189 \pm 0.001 c, d$ \\
\hline FM-SPI30 & $3617 \pm 67 c$ & $3477 \pm 17 c$ & $1.8010^{-3} \pm 8.3110-5 \mathrm{~d}$ & $1.04 \pm 0.005 a$ & $0.172 \pm 0.004 \mathrm{e}$ \\
\hline F/TM-SPI30 & $3228 \pm 18 d$ & $3068 \pm 81 \mathrm{~d}$ & $1.4510^{-3} \pm 1.7910-5 \mathrm{f}$ & $1.05 \pm 0.001 \mathrm{~b}$ & $0.161 \pm 0.001 \mathrm{f}$ \\
\hline FM-SPI45 & $3104 \pm 74 d$ & $2983 \pm 71 d$ & $1.1310^{-3} \pm 4.1110-5 \mathrm{~g}$ & $1.04 \pm 0.003 \mathrm{a}$ & $0.177 \pm 0.002 \mathrm{e}$ \\
\hline F/TM-SPI45 & $2488 \pm 71 \mathrm{e}$ & $2378 \pm 32 \mathrm{e}$ & $1.6310^{-3} \pm 7.8510-5 \mathrm{e}$ & $1.05 \pm 0.001 \mathrm{~b}$ & $0.186 \pm 0.000 \mathrm{~d}$ \\
\hline FM-SPI60 & $1867 \pm 75 \mathrm{f}$ & $1775 \pm 105 \mathrm{f}$ & $1.8810^{-3} \pm 3.0110-5 \mathrm{~d}$ & $1.05 \pm 0.004 \mathrm{~b}$ & $0.197 \pm 0.004 \mathrm{~b}$ \\
\hline F/TM-SPI60 & $1074 \pm 103 \mathrm{~g}$ & $1012 \pm 117 \mathrm{~g}$ & $3.2310^{-3} \pm 6.1010-5 c$ & $1.06 \pm 0.002 c$ & $0.210 \pm 0.001 \mathrm{a}$ \\
\hline LSD (99\%) & 176.08 & 168.31 & $1.1510^{-3}$ & 0.007 & 0.005 \\
\hline
\end{tabular}

a Ratio values correspond to the average value at the linear viscoelastic range. Different lower case letters in the same rheological property column and treatment type indicate significant differences $(P<0.01)$.

characteristic of viscous flow (Mohamed \& Xu, 2003). In addition, a parameter was defined from the stress sweeps to characterise fluid behaviour for the nonlinear viscoelastic range ( $\alpha$, fluid-like relative angle), namely the ratio between $\delta$ measured at $\gamma=2 \times 10^{-1}$ to the phase angle corresponding to a pure fluid $\left(\delta=90^{\circ}\right.$ ) (Navarro et al., 1997). Next three frequency sweeps were performed over the $\omega$ range of $0.1-100 \mathrm{rad} \mathrm{s}^{-1}$, and again the $\delta, G^{\prime}$ and $G^{\prime \prime}$ values were registered at $1 \mathrm{rad} \mathrm{s}^{-1}$. Given that the appearance of the data on logarithmic data was nearly linear, a power law model (Eqs. (1) and (2)) was used to characterise the frequency dependence of both moduli (Alvarez et al., 2011), from the following equations:

$$
G^{\prime}=G_{0}^{\prime} \cdot \omega^{n^{\prime}}
$$

$G \prime \prime=G_{0}^{\prime \prime} \cdot \omega^{n^{\prime \prime}}$

Where $G_{0}^{\prime}$ and $G_{0}^{\prime \prime}$ are elastic and viscous moduli at $1 \mathrm{rad} \mathrm{s}^{-1}$ respectively, and exponents $n^{\prime}$ and $n^{\prime \prime}$ denote the influence degree of $\omega$ on both moduli.

Additionally, the structural differences between MP samples are quantifiable in terms of quality factor $Q$ (Eq. (3)) (angular frequency $6.28 \mathrm{rad} \mathrm{s}^{-1}$ ), a term frequently used in mechanical oscillatory systems. It is dimensionless quantity and represents the degree of damping of an oscillator (Campo-Deaño et al., 2010).

$Q=2 \pi\left(G_{0}^{\prime} / G_{0}^{\prime \prime}\right) \omega^{\left(n^{\prime}-n^{\prime \prime}\right)}$

As a new sample was used each time for the dynamic tests, the resulting values were average values of the four determinations.

\subsection{Large deformation analyses}

Back extrusion (BE) and cone penetration (CP) mechanical tests were performed in order to study the empirical rheological behaviour of the semisolid-like samples. Both experiments were performed using a TA.HDPlus Texture Analyser (Stable Micro Systems Ltd., Godalming, UK) equipped with a $300 \mathrm{~N}$ load cell. During tests, MP samples were kept at $55^{\circ} \mathrm{C}$ by means of a Temperature Controlled Peltier Cabinet (XT/PC) coupled to a separate heat exchanger and a proportional-integral-derivative control unit. To perform BE tests, a rig (model A/BE, Stable Micro Systems) was used consisting of a flat $45 \mathrm{~mm}$ diameter perspex disc plunger that was driven down into a larger perspex cylinder sample holder ( $50 \mathrm{~mm}$ diameter) in order to force the MP samples to flow upwards through the concentric annular space between the plunger and the container. The measuring cup was filled with $50 \pm 1 \mathrm{~g}$ of MPs which were extruded to a distance of $20 \mathrm{~mm}$ at a $2 \mathrm{~mm} \mathrm{~s}^{-1}$ compression rate. At this point (most likely the maximum force), the probe returns to its original position. The area under the curve up to the "peak" or maximum force is taken as a measurement of $\mathrm{BE}$ consistency ( $\mathrm{Ns}$ ), so that the higher the value the thicker the consistency of the sample. For performing the CP tests, a TTC
(Texture Technologies Corporation) spreadability rig (HDP/SR, Stable Micro Systems) was used, consisting of a $45^{\circ}$ conical perspex probe $(\mathrm{P} / 45 \mathrm{C})$ that penetrated a conical sample holder containing $7 \pm 0.1 \mathrm{~g}$ of MP product to a distance of $17.5 \mathrm{~mm}$ at a $3 \mathrm{~mm} \mathrm{~s}^{-1}$ compression rate. The $\mathrm{CP}$ work required per displaced volume $\left(\mathrm{J} \mathrm{m}^{-3}\right)$ to accomplish penetration was calculated from the area under the curve up to the "peak" or maximum penetration force. All measurements were repeated at least four times.

\subsection{Scanning electron microscopy (SEM)}

MP microstructure was examined by using a Hitachi S-2100 scanning electron microscope (Hitachi, Ltd., Tokyo, Japan) (National Center for Metallurgical Research (CENIM)-CSIC). MP samples were air-dried, then mounted and sputter-coated with $\mathrm{Au}$ (200 A approx.) in an SPI diode sputtering system metallizer. Micrographs were taken with a digital system Scanvision 1.2 of Röntgenanalysen-Technik (RONTEC) (GmbH, Berlin, Germany) $(800 \times 1.200$ pixel $)$.

\subsection{Statistical analysis}

A two-way ANOVA with interaction was applied to evaluate how SPI concentration and performance or not of a freeze/thaw cycle affected the rheological and instrumental textural properties. Minimum significant differences were calculated using Fisher's least significant difference (LSD) tests with a $99 \%$ confidence interval. Analysis of variance and correlation was performed by using Statgraphics ${ }^{\circledR}$ software version 5.0 (STSC Inc., Rockville, MD, USA).

\section{Results and discussion}

\subsection{Effect of SPI concentration and freeze/thaw cycle on viscoelastic properties of MP}

The common tests performed using small-amplitude oscillatory shear analyses are stress sweeps (for controlled stress rheometers), frequency sweeps, time sweeps, and temperature sweeps. Stress sweeps of FM potatoes at the different SPI concentrations ( 0 $60 \mathrm{~g} \mathrm{~kg}^{-1}$ ) are shown in Fig. 1. Dynamic curves of storage modulus $G^{\prime}$ (elastic component) and loss modulus $G^{\prime \prime}$ (viscous component) are presented as functions of strain $\gamma$ over four decades of strain at a constant oscillation frequency of $1 \mathrm{rad} \mathrm{s}^{-1}$. Stress sweeps of F/TM potatoes were similar (curves are not shown). As an example, Fig. 1 also shows the complex modulus $G^{*}$ (measurement of the overall resistance (elastic and viscous)) of FM potatoes without added SPI. Similar behaviour was observed for the rest of the samples. This is an appropriate test for analysing the gel character $\left(G^{\prime}>G^{\prime \prime}\right)$ of samples, since as long as the strain amplitudes are below the limiting value $\left(\gamma_{\max }\right)$ the $G^{*}$ pattern has a plateau value, 


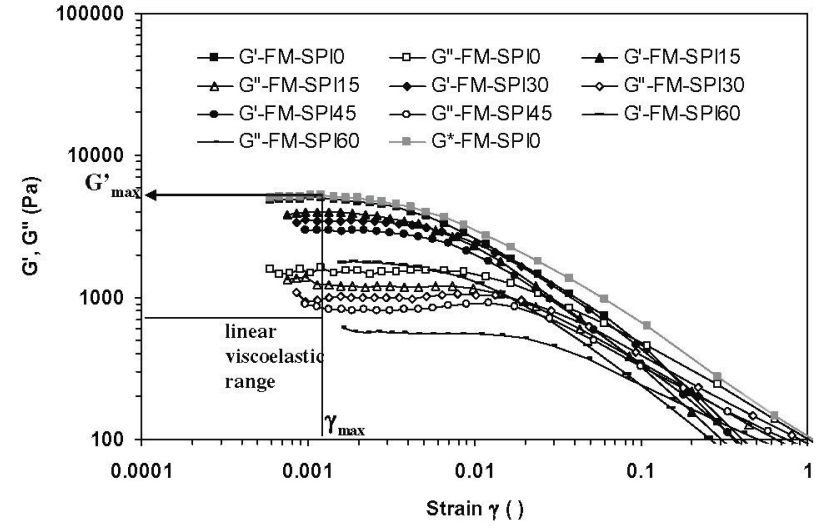

Fig. 1. Typical dynamic curves showing the changes in storage modulus ( $G, P a)$ and loss modulus $\left(G^{\prime \prime}, \mathrm{Pa}\right.$ ) with strain (frequency $1 \mathrm{rad} \mathrm{s}^{-1}$ ) for fresh mashed potatoes (FM) with added SPI at $0,15,3045$ and $60 \mathrm{~g} \mathrm{~kg}^{-1}$.

indicating that the gel structure is stable under these conditions (Campo-Deaño et al., 2010). In all MP samples, both $G^{\prime}$ and $G^{*} \bmod -$ uli showed similar values at low deformations $(<0.003)$, indicative of the low contribution of the viscous component $G^{\prime \prime}$ to the viscoelastic properties of the systems.

The average value of the ratio $G^{*} / G^{\prime}$ calculated for the complete LVE domain ranged from 1.04 to 1.05 in FM potatoes and between 1.04 and 1.06 in F/TMs (Table 1). The highest ratio corresponded to the F/TM-SPI60 samples. Therefore, this result shows that the addition of SPIs at the highest concentration, increased the $G^{\prime \prime}$ contribution to the viscoelastic properties of the F/TM potatoes in the LVE range. As freezing progresses and water migrates to form ice crystals, there is an increase in protein-protein interactions via hydrophobic and ionic forces resulting in further protein denaturation and protein aggregate formation (Xiong, 1997). It is apparent that a freeze/thaw cycle modulates SPI aggregation and gelation depending on SPI concentration and solvent properties (e.g., water activity, $\left.a_{\mathrm{w}}\right)$. It is well known that freezing reduces the $a_{\mathrm{w}}$ due to ice formation and the high concentrations of solutes in unfrozen water (Canet, 1989). A higher SPI content together with a reduced $a_{\mathrm{w}}$ made the water-SPI protein interaction less effective, promoting increased relative motion between domains of the superstructure, then the dissipated energy increases, thus explaining the more viscous-liquid behaviour observed in the F/TM-SPI60 samples.

The LVE range is limited by $G_{\max }^{\prime}$ and $\gamma_{\max }$ (Fig. 1). The LVE domain determined for both FM and F/TM potatoes is shown in Table 1. SPI concentration had a significant effect on maximum strain, but the aspect most worthy of note is that mainly, when comparing the effect of a freeze/thaw cycle on a particular formulation, FM and F/TM samples differed in terms of fragility. At greater SPI concentrations ( 45 and $60 \mathrm{~g} \mathrm{~kg}^{-1}$ ), $\gamma_{\max }$ was significantly lower in the FM samples than in their F/TM counterparts, indicating that F/TM-SPI45 and F/TM-SPI60 samples can withstand higher strains without undergoing structural modifications. One factor accounting for the higher $\gamma_{\max }$ values found in these frozen/thawed samples as compared to their fresh counterparts is that around coarser aggregates, stress amplification will occur (van Vliet, 1988). This may result in the strain being greater nearer the particle than in the linear region. A similar observation was reported by Zhu et al. (2008) for $\kappa$-C and soybean glycinin mixed gels and the authors concluded that both the glycinin and the $\kappa$-C formed a biphasic network.

Outside the LVE region, the viscous component gained in importance and $G^{*}$ values were much greater than $G^{\prime}$ in all systems (Fig. 1). Above the LVE limit, $G^{*}$ and $G^{\prime}$ decreased rapidly in all samples, indicating that the structure was highly prone to deformation.
After structural breakdown, dynamic measurements quantified the liquid-like character of the MP samples characterised by the fluidlike relative angle $\alpha$ as previously defined (Table 1 ). In both FM and F/TM potatoes, $\alpha$ values tended to decrease with increasing SPI concentrations up to $30 \mathrm{~g} \mathrm{~kg}^{-1}$. The lowest $\alpha$ values corresponded to FM-SPI30 and F/TM-SPI30 samples. At SPI concentrations of more than $30 \mathrm{~g} \mathrm{~kg}^{-1}$, the $\alpha$ values again increased. The highest $\alpha$ values were also observed in both FM-SPI60 and F/TM-SPI60 samples, reflecting a more fluid-like behaviour with low viscosity after breakdown $(\alpha \rightarrow 1)$, characterised by a weak structure with poor recovery (Navarro et al., 1997). By adding 15 and $30 \mathrm{~g} \mathrm{~kg}^{-1}$ SPI in the nonlinear range, it is possible that the two main coexisting structures (amylose/amylopectin matrix and SPI aggregates) supplemented each other and the protein properties added to those of the gel matrix present, as reflected by the lower $\alpha$ values obtained for these samples (more solid-like than liquid characteristics).

Note that the FM-SPI45 and FM-SPI60 samples that showed a more significant rigid structure than their F/TM-SPI45 and F/TMSPI60 counterparts in the LVE range (higher $G_{\max }^{\prime}$ values), also had a less significant fluid-like character with superior viscosity after breakdown (Table 1). In contrast, although the FM-SPI30 sample presented a more significant rigid structure than its F/TM-SPI30 counterpart in the LVE range, it had more fluid-like characteristics than the F/TM samples after breakdown (a higher $\alpha$ value). In turn, FM-SPIO and FM-SPI15 samples that showed a slightly less rigid structure than their F/TM-SPI0 and F/TM-SPI15 counterparts in the LVE range (lower $G^{\prime}$ values), also had a more fluid-like character with inferior viscosity after breakdown, even though in the lower SPI concentrations differences between the $\alpha$ values of fresh and processed samples were non-significant. The addition of $30 \mathrm{~g} \mathrm{~kg}^{-1}$ SPI produced a change in rheological behaviour, probably due to the thermodynamic incompatibility typical of a lot of protein-polysaccharide systems (Tolstoguzov, 1985). Thermodynamic incompatibility, on the other hand, involves the spontaneous separation into two solvent-rich phases, one composed predominantly of protein, and the other of polysaccharide. This is caused by demixing nondilute protein and polysaccharide solutions under the influence of net repulsive protein-polysaccharide interactions (Liao, Okechukwu, Damodaran, \& Rao, 1996; Zhu et al., 2008).

$\mathrm{pH}$ has also been mentioned as an important factor in the SPI gelation process (Nagano, Hirotsuka, Mori, Kohyama, \& Nishinari, 1992; Tseng, Xiong, \& Boatright, 2008; Turgeon \& Beaulieu, 2001). SPI behaviour is closely related to the isoelectric point, which is in the region of 4.5 for SPI (Gennadios, Brandenburg, Séller, \& Testin, 1993). As indicated above, the final pH of MP samples ranged from 5.9 to 6 , and therefore the majority of SPI globulins would be negatively charged. Under these conditions, the electrostatic repulsive force between SPI proteins and negatively charged phosphate groups on anionic potato starch would become predominant, thereby preventing interaction between amylose/ amylopectin matrix and protein molecules. In addition, this fact would facilitate the formation of two separated phases. Incompatible polymers, where the different polymers are repulsive and/or when the two types of polymers show varying degrees of affinity towards the solvent, form phase-separated gels (Turgeon \& Beaulieu, 2001). Consequently, as the SPI concentration was increased further, phase separation occurred and $\alpha$ values increased. These results may be useful for process engineering calculations and equipment design in the industrial production of SPI-enriched MP.

To better understand the structural changes that took place in the SPI-based MP structures, the influence of frequency in their viscoelastic properties was studied at $55^{\circ} \mathrm{C}$. Mechanical spectra provide essential information about gel structure and can be used to determine the behaviour of cross-linked proteins which are fixed by chemical bonds, forming a three-dimensional network 
(Campo-Deaño et al., 2010). Fig. 2 shows the evolution of $G^{\prime}$ and $G^{\prime \prime}$ in the LVE range for F/TM potatoes with added SPI at $0-60 \mathrm{~g} \mathrm{~kg}^{-1}$. Similar mechanical spectra, without a qualitative change in the evolution of these functions, were obtained for FM counterparts at each concentration used. In all cases, $G^{\prime}$ was higher than $G^{\prime \prime}$ for the complete $\omega$ range studied, indicating elastic solid behaviour. In each food, the rheological behaviour is directly related to its formulation; the conformational changes experienced by potato starch were largely responsible for the predominantly elastic behaviour of the systems. In addition, double logarithmic plots of $G^{\prime}$ and $G^{\prime \prime}$ versus frequency resulted in straight lines with positive slopes of small magnitude $\left(0.17 \leqslant \mathbf{n}^{\prime} \leqslant 0.20\right.$ for $\mathbf{G}^{\prime}$, and $0.08 \leqslant \mathbf{n}^{\prime \prime} \leqslant 0.15$ for $G^{\prime \prime}$ ). Therefore, based on $G^{\prime}$ and $G^{\prime \prime}$ frequency dependence values, SPI-based MP structures may be classified as weak gels. $G^{\prime \prime}$ tends towards an equilibrium value in which the limited dependence of the frequency indicates the presence of a network arrangement (Alvarez et al., 2011). The higher $n^{\prime}$ and $n^{\prime \prime}$ values were obtained for F/TM-SPI60 samples indicating that these systems possessed networks which were transient in time and involved specific interactions between denser and less flexible particles, such as SPI aggregates. Mainly, when $60 \mathrm{~g} \mathrm{~kg}^{-1}$ SPI was added to the MP, the system clearly showed a less elastic behaviour, reflecting the development of a hindered potato starch three-dimensional internal structure (Fig. 2). The underlying phenomena that determine the observed reduction in rigidity would be dissociation, denaturation, and aggregation of SPI (Puppo et al., 2000; Sorgentini et al., 1995).

In turn, Table 2 shows the effects of SPI concentration and a freeze/thaw cycle on the values of the rheological properties derived from the oscillatory tests at $1 \mathrm{rad}^{-1}$. The analysis of variance showed that SPI concentration had a significant effect $(P<0.01)$ on the $\delta, G^{\prime}, G^{\prime \prime}$ and $Q$ values while a freeze/thaw cycle did not significantly affect the $\delta$ and $Q$ values of the samples. Furthermore, the binary interaction did not significantly affect the oscillatory rheological properties of the samples. This means that the effect of adding SPIs on oscillatory measurements in the LVE range is produced independently of whether or not the systems is subjected to a freeze/thaw cycle. Only the samples with added SPIs at $60 \mathrm{~g} \mathrm{~kg}^{-1}$ had a significantly higher $\delta$ value than the samples without added SPI, again indicating that the highest concentrations of added SPIs produced a decrease in the final gel rigidity. Certainly, no interaction between the amylose/amylopectin matrix and the dispersed SPI particles was established as reflected by a significant decrease in system viscoelasticity ( $G^{\prime}$ and $G^{\prime \prime}$ values) with increasing SPI

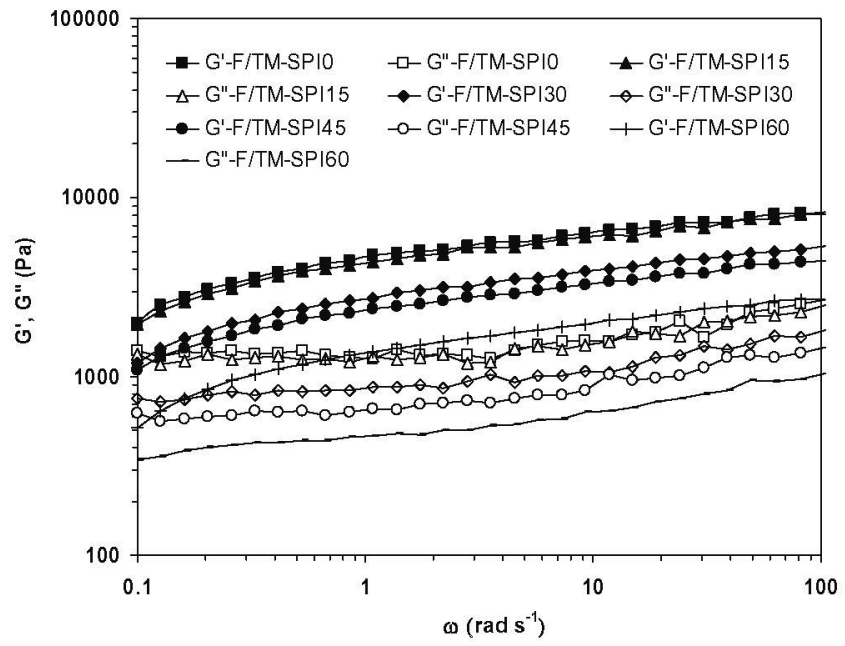

Fig. 2. Dynamic properties, storage modulus $\left(G^{\prime}, \mathrm{Pa}\right)$ and loss modulus $\left(G^{\prime \prime}, \mathrm{Pa}\right)$ versus frequency $\left(\mathrm{rad} \mathrm{s}^{-1}\right)$ for frozen/thawed mashed potatoes (F/TM) with added SPI at $0,15,3045$ and $60 \mathrm{~g} \mathrm{~kg}^{-1}$. concentration (Fig. 2). Likewise, no evidence was observed of any significant interaction between whey protein isolate and $\kappa-\mathrm{C}(\mathrm{He}-$ mar et al., 2002).

$Q$ factor unifies parameters which provide structural information of different kinds: $G_{0}^{\prime}$ and $G_{0}^{\prime \prime}$ are related to the strength of the intermolecular interactions and $n^{\prime}$ and $n^{\prime \prime}$ to the extent and stability of the network (Campo-Deaño et al., 2010). As it can be seen in Table 2, MP samples without added SPIs presented significantly higher $Q$ values; there was a significant lowering of $Q$ factor as SPI concentrations increased, confirming a disruptive effect of SPI aggregates on the amylose/amylopectin network. This behaviour is typical of gels filled with deformable particles (Jampen, Britt, Yada, \& Tung, 2001). According to the latter authors, in gels containing deformable particles, the linear decrease in $G^{\prime}$ in line with increasing volume fractions is due to particle compliance under stress or to particle separation from the matrix, thereby causing gel weakening. The influence of particle-matrix interactions was also studied by van Vliet (1988) who found that a linear decrease in gel strength accompanied by an increase in volume fractions only occurred with non-interacting gel materials. This finding was attributed to the formation of aqueous boundary layers around each particle so that there was no adhesion between the particle and the matrix. The existence of an aqueous boundary layer may be a viable explanation for the data in the present study. As stress is applied to the system, small amounts of water may be released from the gelatinized starch gel, thus forming an aqueous boundary layer around the SPI aggregates. This layer would reduce any interactions with the gel matrix and lead to the formation of weak points in the gelatinized starch gel. Consequently, when these gels suffer small deformations, they behave as if filled with particles with the rheological properties of water.

On the other hand, it is important to clarify that for studying protein gel formation, the common tests performed using smallamplitude oscillatory shear analyses are time sweeps (Nagano et al., 1992). Therefore protein dispersions are consecutively heated from 20 to $95^{\circ} \mathrm{C}$, held at $95^{\circ} \mathrm{C}$ for $30 \mathrm{~min}$, cooled to $20^{\circ} \mathrm{C}$ and then held at $20^{\circ} \mathrm{C}$ for at least $15 \mathrm{~min}$ (Lakemond et al., 2003; Tseng et al., 2008). Generally, the gels undergo major structural development observed especially during the cooling phase, characterised by an increase in both the $G^{\prime}$ and $G^{\prime \prime}$ values. It is well known that heating stabilizes hydrophobic bonds, and that hydrogen bonds are stabilized with decreasing temperature (Puppo et al., 2000 ). In this study, SPI was only heated in the presence of the other ingredients at $90^{\circ} \mathrm{C}$ for $5 \mathrm{~min}$, and then cooled to $55^{\circ} \mathrm{C}$ (see Section 2.2). This brief heat treatment of SPI dissociated the compact glycinin and $\beta$-conglycinin oligomers into monomers and, in doing so, the hydrophobic groups were exposed (Tseng et al., 2008). However, no attempt was made to determine whether the structural changes detected in the MPs via rheological behaviour were sensitive to the time of heating or cooling times. It is expected that a lower cooling temperature and an extension of the cooling phase would result in a further strengthening of the protein structure. However, the thermal conditions for SPIs were in agreement with the standards for preparing this type of semisolid MP product (Alvarez et al., 2011).

Furthermore, both dynamic moduli were higher in the FM samples than in the F/TM ones (Table 2). It has been reported that freeze treatment increased the hydrophobicity of soy protein regardless of the heating treatment (Noh, Kang, Hong, \& Yun, 2006). Because electrostatic interactions are one of the major forces maintaining protein tertiary and quaternary structures, an abrupt increase in ionic strength or salt concentration in the non-frozen phase can cause competition with existing electrostatic bonds, which in turn leads to extensive aggregation of the protein structure (Xiong, 1997). Hence, increased ionic strength associated with freezing leads to the formation of coarser SPI aggregates. 
Table 2

Effects of SPI concentration and a freeze/thaw cycle on oscillatory properties and quality factor Q and large deformation measurements of MP samples.

\begin{tabular}{|c|c|c|c|c|c|c|}
\hline Source & $\delta\left({ }^{\circ}\right)$ & $G^{\prime}(\mathrm{Pa})$ & $G^{\prime \prime}(\mathrm{Pa})$ & $Q$ & $\mathrm{BE}$ consistency $(\mathrm{N} \mathrm{s})$ & CP work per displaced volume $\left(\mathrm{J} \mathrm{m}^{-3}\right)$ \\
\hline \multicolumn{7}{|l|}{ Main effects } \\
\hline \multicolumn{7}{|c|}{ A: SPI concentration $\left(g \mathrm{~kg}^{-1}\right)$} \\
\hline 0 & $15.74 \mathrm{a}$ & $5314.00 \mathrm{a}$ & $1502.12 \mathrm{a}$ & $8.56 \mathrm{a}$ & $57.58 \mathrm{a}$ & $3630.66 \mathrm{a}$ \\
\hline 15 & $16.00 \mathrm{a}$ & $4265.75 \mathrm{~b}$ & $1221.00 \mathrm{~b}$ & $8.20 \mathrm{~b}$ & $52.63 \mathrm{~b}$ & $3723.72 \mathrm{a}$ \\
\hline 30 & $15.90 \mathrm{a}$ & $3247.00 \mathrm{c}$ & $911.45 c$ & $8.13 \mathrm{~b}, \mathrm{c}$ & $48.13 c$ & $3236.96 \mathrm{~b}$ \\
\hline 45 & $15.36 \mathrm{a}$ & $2881.87 \mathrm{~d}$ & $815.60 \mathrm{c}$ & $7.91 \mathrm{c}, \mathrm{d}$ & $50.27 \mathrm{C}$ & $3109.18 \mathrm{~b}$ \\
\hline 60 & $17.97 \mathrm{~b}$ & $1553.25 \mathrm{e}$ & $498.66 \mathrm{~d}$ & $7.70 \mathrm{~d}$ & $37.31 \mathrm{~d}$ & $2726.60 \mathrm{c}$ \\
\hline$P$ values & $<0.001$ & $<0.001$ & $<0.001$ & $<0.001$ & $<0.001$ & $<0.001$ \\
\hline $\operatorname{LSD}(99 \%)$ & 1.49 & 343.50 & 131.23 & 0.29 & 1.81 & 186.54 \\
\hline \multicolumn{7}{|c|}{ B: Freeze/thaw cycle } \\
\hline FM potatoes & $15.76 \mathrm{a}$ & 3711.25 a & $1048.66 \mathrm{a}$ & $8.06 \mathrm{a}$ & $46.71 \mathrm{a}$ & 3477.69 a \\
\hline F/TM potatoes & 16.62 a & $3193.50 \mathrm{~b}$ & $930.87 \mathrm{~b}$ & $8.13 a$ & $51.67 \mathrm{~b}$ & $3093.16 \mathrm{~b}$ \\
\hline$P$ values & 0.017 & $<0.001$ & $<0.001$ & 0.450 & $<0.001$ & $<0.001$ \\
\hline LSD (99\%) & 0.94 & 217.25 & 83.00 & 0.14 & 1.15 & 117.98 \\
\hline \multicolumn{7}{|l|}{ Interaction } \\
\hline \multicolumn{7}{|l|}{$\mathrm{AB}$} \\
\hline$P$ values & 0.484 & 0.053 & 0.208 & 0.899 & $<0.001$ & $<0.001$ \\
\hline
\end{tabular}

Different lower case letters in the same column and factor studied indicate significant differences $(P<0.01)$.

Furthermore, with respect to the F/TM samples in the present study, the microwave thawing treatment (a second heating) probably brought about a loss of solubility and changes in the soluble and insoluble fractions of SPIs. After thawing (heating up to $85^{\circ} \mathrm{C}$ ) additional denaturation and aggregation of the remaining SPI could be expected to occur.

Nevertheless, when the SPI network structure becomes coarser, the ability of the gels to retain water decreases (Lakemond et al., 2003). An increase in the intensity of protein self-association means that water becomes a poorer solvent for the protein but a better solvent for the polysaccharides. Water held within a protein structure is generally categorised into the following two groups: (a) water that is bound to the protein molecule and is not available as a solvent, and (b) trapped water within a protein matrix, which is regarded as retained water (Egbert, 2004). During freezing, the rate and extent of protein-protein interaction could affect the performance of proteins in immobilizing water and ultimately in decreasing the viscoelastic properties of the final product. Analogously, freezing produced an increase in the range of viscous behaviour observed in the mechanical spectrum of unheated whey protein concentrate suspensions, which was attributed to protein aggregation that occurred during freezing (Meza, Verdini, \& Rubiolo, 2010). Unexpectedly, the freeze/thaw cycle effect was not significant for the quality factor $Q$ (Table 2); this result shows that, on the whole, the rheological quality of SPI-MP samples was maintained after freezing and thawing processes.

\subsection{Effect of SPI concentration and freeze/thaw cycle on textural properties of MP}

Typical mechanical profiles taken during $\mathrm{BE}$ and $\mathrm{CP}$ tests are shown in Fig. 3. BE consistency decreased linearly with increasing SPI content in the FM potatoes, although there were nonsignificant differences between the curves shown for FM-SPI15 and FM-SPI30 samples (Fig. 3a). In turn, in the F/TM potatoes, the maximum penetration force, and therefore the $\mathrm{CP}$ work per displaced volume, also decreased linearly with increasing SPI concentrations (Fig. $3 \mathrm{~b}$ ). In $\kappa-\mathrm{C}$ and soybean glycinin mixed gels, hardness decreased significantly as native glycinin concentrations increased, but increased considerably as denatured glycinin increased (Zhu et al., 2008). In the case of the F/TM potatoes, the decrease in CP work per displaced volume with increasing SPI content is consistent with Fig. 2, which shows that $G^{\prime}$ also decreased in the processed samples as the SPI concentration increased from 15 to $60 \mathrm{~g} \mathrm{~kg}^{-1}$.
Table 2 also shows the effects of SPI concentrations and a freeze/thaw cycle on the instrumental textural property values derived from the large deformation tests. The analysis of variance showed that SPI concentrations and the freeze/thaw cycle had a significant effect on both textural properties measured, apart from which binary interaction also significantly affected the textural properties of the MP samples. From variations in the BE consistency values based on SPI concentrations for both FM and F/TM potatoes shown in Fig. 4a, one can observe that SPI content decreased BE consistency in both FM and F/TM samples, although there were non-significant differences between FM-SPI30 and FM-SPI45 and between F/TM-SPI0 and F/TM-SPI15 samples. In the case of FM products, samples with $60 \mathrm{~g} \mathrm{~kg}^{-1}$ of added SPIs had the lowest BE consistency values, while samples with 30 and $45 \mathrm{~g} \mathrm{~kg}^{-1}$ of added SPIs had the highest BE consistency values. In turn, when the amount of added SPs was increased, F/TM samples with $30-60 \mathrm{~g} \mathrm{~kg}^{-1}$ of added SPIs had significantly lower BE consistency values than the SPI-free control. Note that although F/TMSPIO and F/TM-SPI15 samples had significantly higher BE consistency values than their FM-SPI0 and FM-SPI15 counterparts, there were non-significant differences between the BE consistency values for FM and F/TM potatoes with 30 and $45 \mathrm{~g} \mathrm{~kg}^{-1}$ of added SPIs, while the F/TM-SPI60 sample had a significantly lower BE consistency value than its FM-SPI60 counterpart. At F/TM-SPI15 samples, this hardening effect could reflect the effect of dehydration inherent in the process of freeze-denaturation, since water molecules hydrate the protein and act as a lubricant within the protein network. Li et al. (2007) reported that the amount of water covering the surface of a protein in a fully hydrated state was around $0.3 \mathrm{~g} \mathrm{~g}^{-1}$ protein while the water content of a dried protein product was usually less than $0.1 \mathrm{~g} \mathrm{~g}^{-1}$. At higher SPI concentrations, probably the softening produced by the reduced ability of SPI gels to retain water was greater to this hardening effect.

When SPI levels increased, the CP work values evolved differently for each of the FM and F/TM potatoes (Fig. 4b). Whilst in FM potatoes, adding $45 \mathrm{~g} \mathrm{~kg}^{-1}$ SPIs increased the $\mathrm{CP}$ work value, the addition of 15,30 and $60 \mathrm{~g} \mathrm{~kg}^{-1}$ SPIs did not influence CP work. In contrast, the addition of $30-60 \mathrm{~g} \mathrm{~kg}^{-1}$ significantly decreased this $\mathrm{CP}$ work value in the F/TM potatoes. F/TM-SPIO and F/TMSPI15 samples also had significantly higher $\mathrm{CP}$ work values than their FM-SPI0 and FM-SPI15 counterparts, while F/TM-SPI30, F/ TM-SPI45 and F/TM-SPI60 samples had significantly lower CP work values than their fresh counterparts. The results of a freeze/thaw cycle effect on textural measurements are in agreement with those obtained for the fluid-like relative angle $\alpha$ estimated outside the 

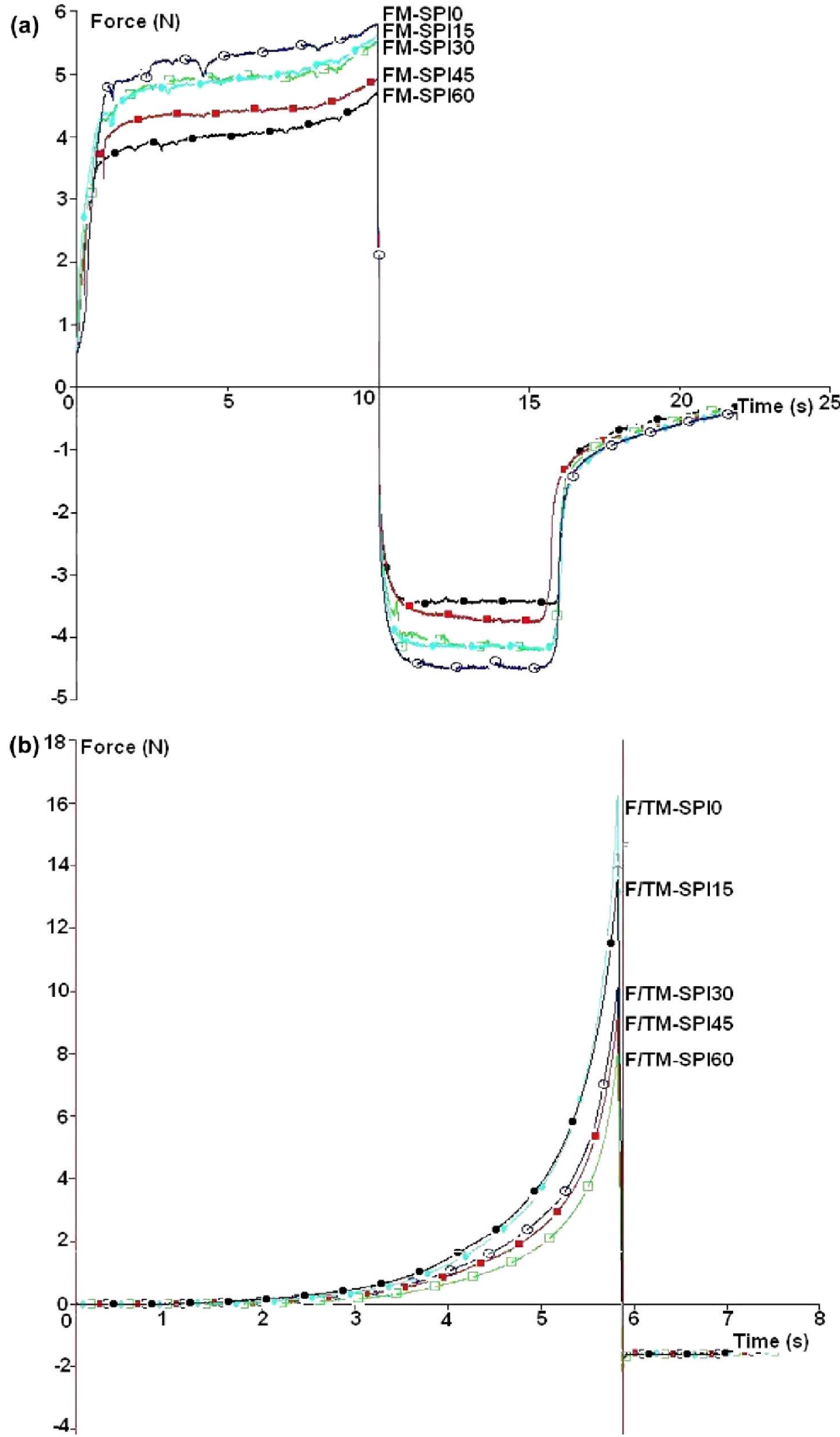

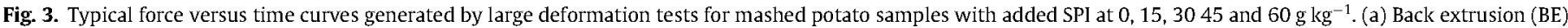
curves of fresh mashed potatoes (FM). (b) Cone penetration (CP) curves of frozen/thawed mashed potatoes (F/TM).

LVE range (Table 1). This result confirms that $30 \mathrm{~g} \mathrm{~kg}^{-1}$ would also appear to be close to the phase separation threshold in SPI-MP samples indicating a change in the rheological behaviour between unfrozen samples as compared to their frozen counterparts. This minimal bulk concentration of SPIs when phase separation occurs depends on the excluded volume of macromolecules, although it was reported that it exceeds $4 \%$ for globular protein-polysaccharides mixtures (Tolstoguzov, 2003). 
a
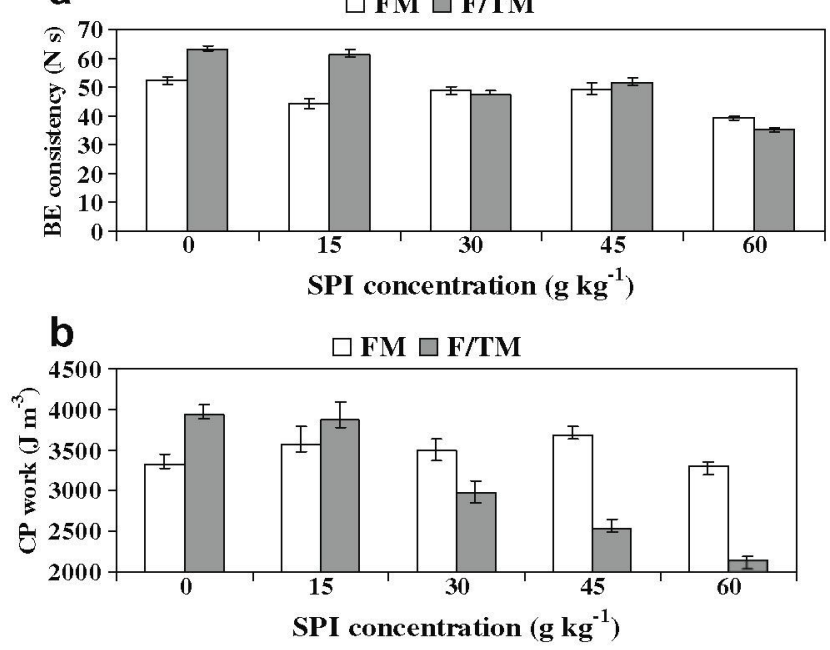

Fig. 4. Large deformation measurements of both fresh (FM) and processed mashed potatoes (F/TM) with added SPI at 0,15,30,45 and $60 \mathrm{~g} \mathrm{~kg}^{-1}$. (a) Back extrusion (BE) consistency. (b) Cone penetration (CP) work per displaced volume.

The relationships between oscillatory rheological properties and instrumental texture parameters were determined by multiple correlations (data not shown). Although there was significant correlation between $B E$ consistency and both dynamic $G^{\prime}$ and $G^{\prime \prime}$ moduli $(r=0.72)$, as well as between CP work and both viscoelastic properties $(r=0.67)$, these correlations were quite low showing that small and large deformation tests responded differently to the structure. Different trends in small and large deformation rheological tests were also found by Ravindra, Genovese, Foegeding, and Rao (2004). Data on the increase or decrease in gel moduli with increasing volume fractions of filler obtained under small deformation test conditions may not simply be extended to the increase or decrease in gel strength when subjected to large deformations, although if there is interaction between the matrix and the filler material some similarities may be observed (van Vliet, 1988). Interestingly, in this study, when considering the F/TM samples separately, quite high correlations between viscoelastic properties and large deformation measurements $(r \geqslant 0.94)$ were established.

\subsection{Microstructure examination}

To achieve a better understanding of the rheological results and the effect of SPI concentrations and freezing, the microstructure of the systems was studied by SEM. Microphotographs of FM and F/ TM potatoes without and with added SPIs at the intermediate $\left(30 \mathrm{~g} \mathrm{~kg}^{-1}\right)$ and highest SPI concentrations used are shown in Fig. 5. Cracks and differences in colour should be disregarded as they are not features of the different samples but a problem of sample preparation and image generation respectively. As shown by the rheological results, the effect of SPI on the microstructure depended on either SPI concentration or on whether the systems was subjected to a freeze/thaw cycle or not.

Both FM and F/TM samples without added SPIs (Figs. 5a and d) consist mainly of a continuous phase (amylose/amylopectin matrix) due to the disruption and complete solubilisation of the potato starch granules by heating. Micrographs revealed the presence of cell wall cementing materials as well as cell fragments are embedded in the continuous solubilised starch matrix. In all the FM products, the shape of the potato cells could still be observed (Figs. $5 a-c$ ). In both SPI concentrations (Figs. 5b, c, e and f), a protein network structure can be seen composed of protein aggregate clumps and small SPI clusters, which are clearly distinguishable from the starch matrix. In the case of globular proteins two different types of gel network can be observed: fine-stranded and coarse networks (Lakemond et al., 2003). There are three major influences that determine the nature of the protein gel formed: (1) environmental conditions, such as $\mathrm{pH}$, ionic strength, and mineral content; (2) protein composition, extent of denaturation, and concentration; and (3) processing conditions, such as heating and cooling rates (Turgeon \& Beaulieu, 2001). The addition of cations (Mohamed \& Xu, 2003) or $\mathrm{pH}$ values near the isoelectric point (over $\mathrm{pH} 4-6$ ) results in less electrostatic repulsion between protein components thereby allowing aggregation prior to gel formation. The MP samples studied here contain either $\mathrm{Na}^{+}$, from salt incorporation, or $\mathrm{Ca}^{2+}$ ions, proceeding mainly from added milk. The presence of both cations in the systems may possibly have led to an enhanced hydrophobic association of soy proteins, favouring the formation of these opaque gels defined as white aggregate or particulate gels. Tseng et al. (2008) also observed that SPI gels exhibited a particulate porous network structure.

In the F/TM samples (Figs. $5 d-f$ ), the tissue presents a more dehydrated appearance, since part of the intracellular water was drawn out osmotically when the product was thawed, due to a freezing-induced concentration of the cell mass and reduced water activity (Canet, 1989). Notably, most of the cells lost their spherical shape and were visibly shrunken, a fact which was also reflected in decreased rheological properties. Micrographs confirm that there was no thermal interaction between potato starch and SPIs, and two phases can be appreciated. Mixtures of $\kappa$-C with skimmed
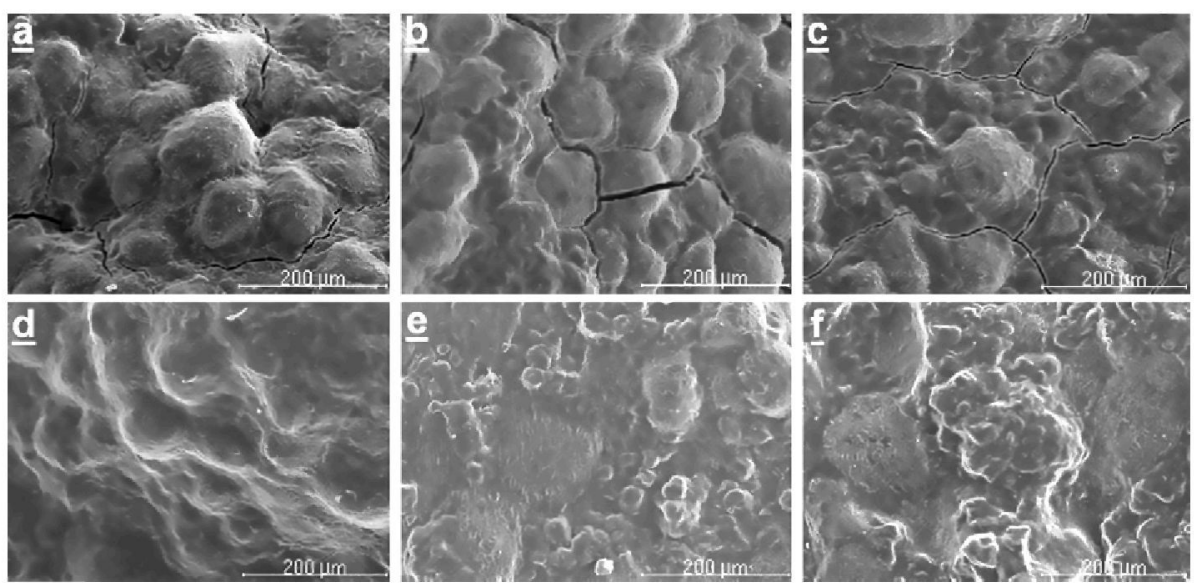

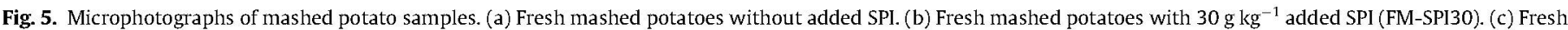

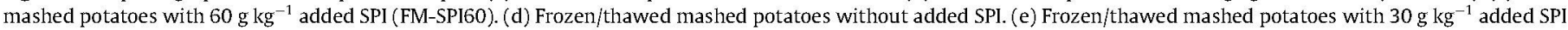
(F/TM-SPI30). (f) Frozen/thawed mashed potatoes with $60 \mathrm{~g} \mathrm{~kg}^{-1}$ added SPI (F/TM-SPI60). 
milk powder, milk protein concentrate, and sodium caseinate also showed phase separation (Hemar et al., 2002). Thermodynamic incompatibility (electrostatic repulsion and water partition between molecules) promoted association between macromolecules of the same type, i.e. facilitated self-association of biopolymers (Tolstoguzov, 1985).

On the other hand, an increase in the intensity of protein selfassociation (the quantity of SPI clusters was higher) was observed by increasing SPI concentration or after a freeze/thaw cycle (Figs. $5 \mathrm{c}$ and $\mathrm{f}$ ). The freeze/thaw cycle mainly enhanced the aggregation tendency of unfolded protein molecules thus increasing the particulate network. Apart from the foregoing, a pH value of 5.9/6 in combination with a high SPI concentration could have enhanced protein aggregation through attractive electrostatic interaction between the different SPI components (Nagano et al., 1992), producing sizeable and loosely associated clusters of aggregates. Samples with added $60 \mathrm{~g} \mathrm{~kg}^{-1} \mathrm{SPI}$, which had the largest aggregates in SEM, also had the lowest $G^{\prime}$ values. It was also suggested that the bigger particles disrupted the matrix because they did not "fit" into the void spaces of the matrix (Jampen et al., 2001). Particle size differences may therefore partly account for the MPs rigidity minima obtained with higher SPI concentrations. The force applied to the system would be expected to result in deformation or energy absorption in both the amylose/amylopectin matrix and the SPI aggregate itself, leading to an overall structure characterised by lower rigidity.

\section{Conclusion}

As the stimulus in texture perception is predominantly mechanical in nature, small and large deformation rheological measurements have been used to arrive at a mechanistic understanding of SPI-based MP systems. Both FM and F/TM potatoes with added SPIs can be considered as macromolecular gels containing dispersed SPI aggregates (fillers), which behave as deformable particles. This transition from a completely continuous phase (amylose/amylopectin matrix) to a system where the SPI aggregates are dispersed is shown by a decrease in system viscoelasticity ( $G^{\prime}$ and $G^{\prime \prime}$ values) and large deformation measurements. Consequently, there is no interaction between the potato gel matrix and the dispersed SPI particles. The principal cause would appear to be the electrostatic repulsive force between the negatively charged SPI globulins and the anionic potato starch. The structures of the systems were even weakened to a greater extent by the freeze/thaw cycle, mainly because the gel properties (elasticity and viscosity) of the amylose/amylopectin matrix were reduced by coarsening of the SPI network structure associated with a decreased ability to retain water. $30 \mathrm{~g} \mathrm{~kg}^{-1}$ SPI would appear to be close to the phase separation threshold in SPI-MP samples, revealing a change in rheological behaviour due to thermodynamic incompatibility between solubilised potato starch and SPI. Despite the results obtained, matching the rheological behaviour of SPIbased MPs does not guarantee a corresponding matching of the sensory-perceived texture. A thorough knowledge of the sensory properties of the systems is subsequently needed. It is expected that, by adopting the texture-modifying properties of SPI, functional MPs can be prepared.

\section{Acknowledgements}

The authors wish to thank the Spanish Ministry of Science and Innovation for its financial support (AGL2007-62851), as well as P. Adeva, I. Amurrio and A. García of the electron miscroscopy laboratory (CENIM-CSIC).

\section{References}

Alvarez, M. D., Fernández, C., \& Canet, W. (2009). Enhancement of freezing stability in mashed potatoes by the incorporation of kappa-carrageenan and xanthan gum blends. Journal of the Science of Food and Agriculture, 89, 2115-2127.

Alvarez, M. D., Fernández, C., Solas, M. T., \& Canet, W. (2011). Viscoelasticity and microstructure of inulin-enriched mashed potatoes: influence of freezing and cryoprotectants. Joumal of Food Engineering, 102, 66-76.

Campo-Deaño, L., Tovar, C. A., \& Borderías, J. (2010). Effect of several cryoprotectants on the physicochemical and rheological properties of suwari ges from frozen squid surimi made by two methods. Journal of Food Engineering, 97, 457-464.

Canet, W. (1989). Quality and stability of frozen vegetables. In S. Thorne (Ed.), Developments in food preservation (pp. 1-50). London: Elsevier.

Egbert, W. R. (2004). Isolated soy protein: Technology, properties and applications. In K. Liu (Ed.), Soybeans as functional foods and ingredients (pp. 135-162). USA: AOCS Publishing.

Federal Register (1998). Food labeling: health claim soy protein and coronary heart disease. Federal Register, 63, 62977-63015.

Gennadios, A., Brandenburg, A. H. Séller, C. L., \& Testin, R. F. (1993). Effect of pH on properties of wheat gluten and soy protein isolate films. Journal of Agricultural and Food Chemistry, 41, 1835-1839.

Hashizume, K., Kakiuchi, K., Koyama, E., \& Watanabe, T. (1971). Denaturation of soy protein by freezing. Agricultural and Biological Chemistry, 35, 449-459.

Hemar, Y., Hall, C. E., Munro, P. A., \& Singh, H. (2002). Small and large deformation rheology and microstructure of $\kappa$-carrageenan gels containing commercial milk protein products. International Dairy Journal, 12, 371-381.

Jampen, S., Britt, l. J., Yada, S., \& Tung, M. A. (2001). Rheological properties of gellan gels containing filler particles. Journal of Food Science, 66, 289-293.

Lakemond, C. M. M., de Jongh, H. H. J., Paques, M., van Vliet, T., Gruppen, H., \& Voragen, G. J. (2003). Gelation of soy glycinin; influence of $\mathrm{pH}$ and ionic strength on network structure in relation to protein conformation. Food Hydrocolloids, 17 , 365-377

Li, X., Li, Y., Hua, Y., Qiu, A., Yang, C., \& Cui, S. (2007). Effect of concentration, ionic strength and freeze-drying on the heat-induced aggregation of soy proteins. Food Chemistry, 104, 1410-1417.

Liao, H.-J., Okechukwu, P. E., Damodaran, S., \& Rao, M. A. (1996). Rheological and calorimetric properties of heated corn starch-soybean protein isolate dispersions. Journal of Texture Studies, 27, 403-418.

Meza, B. E., Verdini, R. A., \& Rubiolo, A. C. (2010). Effect of freezing on the viscoelastic behaviour of whey protein concentrate suspensions. Food Hydrocolloids, 24, 414-423.

Mohamed, A., \& Xu, J. (2003). Effect of ionic strength and $\mathrm{pH}$ on the thermal and rheological properties of soy protein-amylopectin blend. Food Chemistry, 83, 227-236.

Nagano, T., Hirotsuka, M., Mori, H., Kohyama, K., \& Nishinari, K. (1992). Dynamic viscoelastic study on the gelation of 75 globulin from soybeans. Joumal of Agricultural and Food Chemistry, 40, 941-944.

Navarro, A. S., Martino, M. N., \& Zaritzky, N. E. (1997). Correlation between transient rotational viscometry and a dynamic oscillatory test for viscoelastic starch based systems. Journal of Texture Studies, 28, 365-385.

Noh, E. J., Kang, C., Hong, S. T., \& Yun, S. E. (2006). Freezing of soybeans influences the hydrophobicity of soy protein. Food chemistry, 97, 212-216.

Puppo, M. C., Sorgentini, D. A., \& Añón, M. C. (2000). Rheological study of dispersions prepared with modified soybean protein isolates. Journal of the American Oil Chemists' Society, 77, 63-71.

Ravindra, P., Genovese, D. B., Foegeding, E. A., \& Rao, M. A. (2004). Rheology of heated mixed protein isolate/cross-linked waxy maize starch dispersions. Food Hydrocolloids, 18, 775-781.

Sorgentini, D. A., Wagner, J. R., \& Añón, M. C. (1995). Effects of thermal-treatment of soy protein isolate on the characteristics and structure-function relationship of soluble and insoluble fractions. Journal of Agricultural and Food Chemistry, 43 2471-2479.

Soya - Information about Soy and Soya Products. <http://www.soya.be/soyprotein-health-claim.php>.

Tolstoguzov, V. B. (1985). Functional properties of protein-polysaccharide mixtures. In J. R. Mitchell \& D. A. Ledward (Eds.), Functional properties of food macromolecules (pp. 171-202). New York: Elsevier Science.

Tolstoguzov, V. (2003). Thermodynamic considerations of starch functionality in foods. Carbohydrate Polymers, 51, 99-111.

Tseng, Y.-C., Xiong, Y. L., \& Boatright, W. L. (2008). Effects of inulin/oligofructose on the thermal stability and acid-induced gelation of soy proteins. Journal of Food Science, 73, E44-E50.

Turgeon, S. L., \& Beaulieu, M. (2001). Improvement and modification of whey protein gel texture using polysaccharides. Food Hydrocolloids, 15, 583-591.

van Vliet, T. (1988). Rheological properties of filled gels: Influence of filler matrix interaction. Colloid and Polymer Science, 266, 518-524.

Xiong, Y. L. (1997). Protein denaturation and functionality losses. In M. C. Erickson \& Y.-C. Hung (Eds.), Quality in frozen foods (pp. 111-140). New York: Chapman \& Hall.

Zhu, J. H., Yang, X. Q., Ahmad, I., Li, L., Wang, X. Y., \& Liu, C. (2008). Rheological properties of $\kappa$-carrageenan and soybean glycinin mixed gels. Food Research International, 41, 219-228. 